\title{
RESEARCH
}

Open Access

\section{Effect of commercial wearables and digital behaviour change resources on the physical activity of adolescents attending schools in socio-economically disadvantaged areas: the RAW-PA cluster- randomised controlled trial}

\author{
Nicola D. Ridgers ${ }^{1 *}$ D, Anna Timperio ${ }^{1}$, Kylie Ball ${ }^{1}$, Samuel K. Lai ${ }^{1}$, Helen Brown', Susie Macfarlane ${ }^{2}$ and Jo Salmon ${ }^{1}$
}

\begin{abstract}
Background: There has been increasing interest in using wearable activity trackers to promote physical activity in youth. This study examined the short- and longer-term effects of a wearable activity tracker combined with digital behaviour change resources on the physical activity of adolescents attending schools in socio-economically disadvantaged areas.

Methods: The Raising Awareness of Physical Activity (RAW-PA) Study was a 12-week, multicomponent intervention that combined a Fitbit Flex (and accompanying app), and online digital behaviour change resources and weekly challenges delivered via Facebook. RAW-PA was evaluated using a cluster-randomised controlled trial with 275 adolescents (50.2\% female; $13.7 \pm 0.4$ years) from 18 Melbourne secondary schools (intervention $n=9$; wait-list control group $n=9$ ). The primary outcome was moderate- to vigorous-intensity physical activity (MVPA), measured using hip-worn ActiGraph accelerometers. The secondary outcome was self-reported physical activity. Data were collected at baseline, 12-weeks (immediately post-intervention), and 6-months post-intervention (follow-up). Multilevel models were used to determine the effects of the intervention on daily MVPA over time, adjusting for covariates.

Results: No significant differences were observed between intervention and wait-list control adolescents' deviceassessed MVPA immediately post-intervention. At 6-months post-intervention, adolescents in the intervention group engaged in 5 min ( $95 \% \mathrm{Cl}$ - 9.1 to - 1.0) less MVPA per day than those in the wait-list control group. Males in the intervention group engaged in $11 \mathrm{~min}(95 \% \mathrm{Cl}$ - 17.6 to -4.5$)$ less MVPA than males in the wait-list control group at 6-months post-intervention. No significant differences were observed for females at either time point. For selfreported physical activity, no significant effects were found at 12-weeks and 6-months post-intervention.

(Continued on next page)
\end{abstract}

\footnotetext{
* Correspondence: nicky.ridgers@deakin.edu.au

${ }^{1}$ Institute for Physical Activity and Nutrition (IPAN), School of Exercise and Nutrition Sciences, Deakin University, Geelong, Australia

Full list of author information is available at the end of the article
}

(c) The Author(s). 2021 Open Access This article is licensed under a Creative Commons Attribution 4.0 International License, which permits use, sharing, adaptation, distribution and reproduction in any medium or format, as long as you give appropriate credit to the original author(s) and the source, provide a link to the Creative Commons licence, and indicate if changes were made. The images or other third party material in this article are included in the article's Creative Commons licence, unless indicated otherwise in a credit line to the material. If material is not included in the article's Creative Commons licence and your intended use is not permitted by statutory regulation or exceeds the permitted use, you will need to obtain permission directly from the copyright holder. To view a copy of this licence, visit http://creativecommons.org/licenses/by/4.0/. The Creative Commons Public Domain Dedication waiver (http://creativecommons.org/publicdomain/zero/1.0/) applies to the data made available in this article, unless otherwise stated in a credit line to the data. 
(Continued from previous page)

Conclusions: Combining a wearable activity tracker with digital behaviour change resources and weekly challenges did not increase inactive adolescents' accelerometer-derived and self-reported physical activity levels immediately post-intervention. This contrasts previous research that has suggested wearable activity tracker may increase youth physical activity levels in the short-term. Lower engagement in MVPA 6-months post-intervention was observed for males but not for females, though it is unclear why this finding was observed. The results suggest wearable activity trackers, in combination with supporting materials, may not be effective for increasing physical activity levels in adolescents.

Trial registration: ACTRN12616000899448. Australian and New Zealand Clinical Trials Registry. Registered 7 July 2016.

Keywords: Intervention, Adolescents, Physical activity, Wearable activity tracker, Social media

\section{Background}

It has been well documented that higher levels of physical activity benefit adolescents' physical, social, and mental health $[1,2]$. Despite this, $80 \%$ of adolescents aged $13-15$ years old engage in less than the recommended $60 \mathrm{~min}$ of moderate- to vigorous-intensity physical activity (MVPA) every day [3]. Steep declines in physical activity have been shown to occur during adolescence [4], with greater decreases observed among those living in socioeconomically disadvantaged areas [5]. As such, there is a need to develop and test strategies that aim to increase physical activity levels in adolescents living in socioeconomically disadvantaged areas, who are an under-represented group in physical activity interventions [6].

Wearable activity trackers have been the leading fitness trend in recent years [7], and widespread uptake has been reported within different population age groups $[7,8]$. Unsurprisingly, there has been considerable interest among researchers and practitioners in the potential that wearable trackers available to consumers offer for physical activity promotion [9, 10]. Rapid advances in technology have resulted in the automation of real-time activity tracking against individualised goals and public health recommendations, enabling the wearer to self-monitor their activity over a prolonged period of time [11, 12]. Selfmonitoring has been well established as an effective behaviour change technique in promoting adoption of targeted health behaviours such as physical activity [13]. When wearable physical activity trackers are combined with an accompanying app and/or website platform, this 'self-monitoring system' provides an individual with access to a range of features and functions that have been shown to align with up to 26 different behaviour change techniques that are known to be effective [13-15].

Wearable activity trackers have generally been shown to have acceptable validity for measuring steps [16], but little research has examined whether these devices are effective in increasing physical activity levels [11, 17, 18], or how they are used within interventions [9]. In adults the research findings are mixed, with some studies suggesting wearable activity trackers may increase activity levels, yet others suggesting activity declines after initial short-term increases [19-21]. Of the few studies conducted with adolescents, wearable activity trackers have been combined with additional strategies such as goal setting [22, 23], incentives [24], or online educational programs [25] to encourage and support engagement in physical activity. However, the majority of studies have been feasibility pilot interventions delivered over a short time period, lacking longer-term follow-up assessments, involving small samples, and few included adolescents living in socioeconomically disadvantaged areas $[11,18]$. Combining social media platforms and online programs alongside wearable trackers is a promising approach for promoting physical activity in adolescents, since these strategies can reach a large proportion of the target audience due to high home internet availability, may motivate participants, and can provide information to educate and upskill individuals in behaviour change techniques [26-28]. However, to date few significant effects on physical activity have been reported [29, 30].

The aim of this study was to examine the 12-week intervention and 6-month maintenance effects of a wearable activity tracker combined with digital behaviour change resources on the physical activity of adolescents attending schools in socio-economically disadvantaged areas.

\section{Methods}

\section{Study design and participants}

The Raising Awareness of Physical Activity (RAW-PA) Study was a 12-week multi-component intervention that combined a wearable activity tracker and supporting digital materials that targeted adolescents attending schools in socioeconomically disadvantaged areas. The RAW-PA Study rationale and protocols have been reported in detail elsewhere [31]. The CONSORT statement for cluster randomised controlled trials [32] and the TIDieR checklist [33] are used in the reporting of this study. The CONSORT checklist and the TIDieR checklist are provided in Additional file 1 and 2, 
respectively. In brief, the intervention was evaluated using a cluster-randomised controlled trial with measures conducted at baseline, immediately postintervention (12 weeks), and 6-months post-intervention. Schools within $\sim 60 \mathrm{~km}$ of Deakin University's Burwood Campus with a Socio-Economic Indexes for Areas (SEIF A) [34] score of $\leq 5$ (lowest $50 \%$ ) were eligible to participate. Eighteen secondary schools (42\% response rate) provided written informed Principal consent to participate in the study. Following baseline assessments, schools were paired based on SEIFA score and size and randomly allocated to either the intervention ( 9 schools) or wait-list control ( 9 schools) group using a computerbased random number generator [31]. An independent researcher who was not involved in the study conducted the randomisation process.

Students were eligible to participate in the intervention if they were in Year 8, at least 13 years old, had access to the internet outside of school (e.g., via smartphone or home internet), self-reported that they did not engage in regular physical activity/sport, did not meet current physical activity guidelines, and reported that they had not previously owned or used a wearable activity tracker. Students were provided recruitment information by a liaison teacher in each participating school, and eligibility was determined based on a checklist completed by the students and their parents. In total, 280 adolescents ( $20 \%$ of students in Year 8 at participating schools) selfidentified as meeting the inclusion criteria and provided written informed parental consent and student assent to participate in the study. Ethics approval for this study was received from the Deakin University Human Research Ethics Committee (2016-179) and the Victorian Department of Education and Training. The study is registered with the Australian and New Zealand Clinical Trials Registry (No: ACTRN12616000899448).

\section{Power calculation}

The sample size was based on detecting differences in daily MVPA between the intervention and wait-list control students immediately post-intervention [31]. Based on an initial sample size of 300 students (150 per group), and assuming an $\alpha$ of 0.05 , power of $80 \%$, and a $30 \%$ dropout rate, it was calculated that this study would be powered to detect a difference in daily MVPA of $7.9 \mathrm{~min}$ between intervention and wait-list control students. A difference of $10 \mathrm{~min}$ has previously found to be clinically meaningful [35]; a difference of this magnitude that this study was powered to detect.

\section{Intervention}

RAW-PA was informed by and developed using participatory research principles. Adolescents in Year 8 were involved in designing and reviewing the intervention approach, components, and materials. A detailed description of this process and the intervention has been previously reported $[31,36]$. In brief, students provided their thoughts on how to integrate wearable activity trackers into a physical activity intervention. Feedback was provided on the format and content of behaviour change resources, for example, and developed materials were refined further based on additional suggestions [31]. RAW-PA was grounded in Behavioural Choice Theory [37] and Social Cognitive Theory [38], and targeted key intrapersonal (e.g., enjoyment, self-efficacy) and interpersonal (e.g., teachers, peers) influences on health behaviour (see [31] for details). The intervention included the following components: a Fitbit Flex and accompanying app (provided free of charge); interactive weekly individual and/or team 'missions' and behaviour change resources accessible via a private, researchermoderated Facebook group, and alerts (e.g. text messages) to new online content [31]. The weekly missions were posted in the Facebook group at the start of each week by the research team. The missions were designed to help students learn and develop behaviour change techniques (e.g. goal setting, self-monitoring, selfefficacy) that have been established as effective for changing health behaviours [13], and focused on increasing physical activity by incorporating more movement into daily life. There were 12 weekly missions including, for example, "Pair Up!", which focused on engaging in physical activity with friends, and "Step it Up!", which focused on evaluating and adjusting set goals [31]. The accompanying behaviour change resources (e.g. infographics, short videos) were matched to the weekly mission to communicate and reinforce key messages. The online mode of delivery of the missions and resources via the Facebook group ensured that the information was readily available and enabled students to engage with the content in their own time. Alerts to new content were sent 2-3 times a week. The private Facebook group was also intended to be a supportive social forum for sharing experiences with other students at intervention schools and the research team during the intervention. For practical reasons, RAW-PA was delivered across three different waves between September 2016 and October 2017, with schools participating in one wave. Participants in the paired schools (wait-list control) received the intervention at the completion of the 6-month post-intervention assessments.

\section{Wearable activity tracker}

The intervention used the Fitbit Flex ( AUS \$100), which is a wrist-worn monitor that provides estimates of steps taken, physical activity intensities, estimated energy expenditure, and sleep duration. Feedback on steps taken is provided to the wearer via a visual display 
consisting of five light emitting diode (LED) indicator lights which light up as the individual progresses towards their individualised daily goal created during the Fitbit Flex set-up process (one light represents $20 \%$ of the goal achieved). To view more detailed information on collected data, participants were required to sync the device with their online Fitbit account. This free account is accessed using the Fitbit smartphone app or via the Fitbit website. The Fitbit Flex requires charging approximately every 5 days and stores data for up to 7 days without being synced to the user's account [36]. At the start of the intervention, research staff assisted students in setting up the device and their Fitbit profile, and provided initial information about how to charge and sync the device. This information was also provided within the packaging of the device. At the end of the 12week intervention period, adolescents in the intervention group and wait-list control kept the Fitbit Flex as compensation for participation.

\section{Measures}

A survey containing questions about demographic characteristics (e.g., marital status, employment status, education) was completed by the adolescents' parents at baseline. The highest reported parental education was used as a proxy-measure of socio-economic status and was classed as low (some high school attendance or less), medium (high school or trade certificate completed), or high (tertiary education).

Trained research assistants completed data collection with adolescents in schools at each time point using standardised protocols unless otherwise specified. Research staff were not blinded to treatment allocation at 12-week post-intervention or at 6-month post-intervention.

\section{Accelerometry}

Students' physical activity levels were objectively assessed for 8 consecutive days using a hip-mounted ActiGraph GT3X+ accelerometer (Pensacola, FL, USA) at each time point. The accelerometer has acceptable reliability and validity for use in this population [39]. Students were instructed to wear the accelerometer during waking hours and only remove it for water-based activities and sleeping. Raw data were sampled at $30 \mathrm{~Hz}$ and downloaded into 15 epochs for analysis. Age-specific thresholds were used to determine time spent in moderate- to vigorous-intensity physical activity (MVPA [40];). Non-wear time was defined as $60 \mathrm{~min}$ of consecutive zeroes [41]. A valid day was defined as $\geq 8 \mathrm{~h}$ on weekdays and $\geq 7 \mathrm{~h}$ on weekends to maximise sample retention [42]. Data at each time point were included for analyses if the accelerometer had been worn for at least 3 days [42]. Complete (valid) accelerometer data were collected from 246 students at baseline. Immediately post- intervention and 6-month post-intervention, valid accelerometry data were collected from 198 and 193 students, respectively.

\section{Survey data}

Students completed a questionnaire on an iPad at each time point that included questions concerning demographic information (e.g. sex, age, date of birth). Surveys were administered at the student's school by trained research assistants. If a student was absent on the scheduled data collection visit, they completed a hard copy survey on their return to school under the supervision of their teacher. The surveys included assessments of leisure-time physical activity and sedentary time, potential mediators of behaviour change, and process measures (e.g. acceptability, appeal of RAW-PA intervention [31]). A comprehensive process evaluation has been undertaken and is published elsewhere [43]. For the purpose of this study, questions that asked students to selfreport the number of days (0-7) on which they had engaged in MVPA for a total of 60 min per day over the past 7 days and over a typical week were analysed [44]. A definition of MVPA and examples of physical activities were provided, and students were asked to sum the time spent in MVPA each day. The two items responses were averaged for use in the analyses [44]. These items have been validated for use with adolescents [44, 45].

\section{Statistical analyses}

Descriptive analyses were initially conducted for all measured variables. Analyses were performed using the intention-to-treat principle, with students analysed according to the group to which their school was randomised [46]. To determine the effects of the intervention on daily MVPA and whether effects were maintained over time, multilevel models were used. As multilevel model analyses are robust to missing data points, do not require complete data sets, and can estimate effects over time using incomplete data sets, all collected data that met the inclusion criteria at each time point were used in the analyses $[47,48]$. Missing data were assumed to be missing at random. A three-level model was used: time point (Level 1); adolescent (Level 2); and school (Level 3). The random structure considered random intercepts. Time (12 week post-intervention, 6-month postintervention) and intervention group (intervention, waitlist control) were included as fixed factors. The initial model was adjusted for baseline values and accelerometer wear time (when accelerometer data were analysed). The final model additionally adjusted for sex, baseline age, and wave of data collection. A sex by time interaction term was calculated and where significant, sub-group analyses by sex were undertaken. A sensitivity analysis was conducted for completers (i.e. participants who provided 
complete data at baseline, immediately post-intervention, and 6-month post-intervention). Statistical significance was set at $p<0.05$. All analyses were conducted using Stata SE v15 (StataCorp, Texas, USA).

\section{Results}

The flow of the participants through the study is shown in Fig. 1. Five students withdrew from the study prior to baseline assessments, resulting in a sample of 275 adolescents $(51.6 \%$ female). This represented $91.7 \%$ of the target sample. At baseline, 264 students ( $52.3 \%$ female) received an accelerometer and 265 students $(52.1 \%$ female) completed a survey (Fig. 1). In total, 267 parents returned a survey. Based on the 258 parents who provided information about parental education, 32.2 and $37.6 \%$ were classed as low and medium socio-economic status, respectively. Descriptive baseline information for the adolescents is presented in Table 1.

\section{Main analyses}

Table 2 reports the intervention effects (partially-adjusted and fully-adjusted models) on MVPA and selfreported physical activity for the intervention group compared to the wait-list control group immediately post-intervention and at 6-month post-intervention. Significant sex by time interactions were found for MVPA and self-reported physical activity $(p<0.05)$. No significant intervention effects for daily MVPA were found immediately post-intervention in the whole sample and for males and females. At 6-month post-intervention, students in the intervention group engaged in significantly less MVPA than students in the wait-list control group (adjusted model: $-5.0 \mathrm{~min}$; 95\% CI: -9.1 to -1.0 ). Subgroup analyses found that males in the intervention group engaged in significantly less MVPA than males in the wait-list control group (adjusted model: $-11.0 \mathrm{~min}$; 95\% CI: -17.6 to -4.5$)$ at 6 -month post-intervention. No significant intervention effects were observed for females' MVPA at 6-month post-intervention. For selfreported physical activity, no significant intervention effects were found immediately post-intervention or at 6-month post-intervention for the whole sample or in the sub-group analyses.

\section{Sensitivity analyses}

The pattern of results for MVPA $(n=150)$ and selfreported physical activity $(n=221)$ were similar when comparing results for completers only with the respective results in the main analyses (Additional file 3).

\section{Discussion}

This study aimed to examine the 12-week postintervention and 6-month maintenance effects of a wearable activity tracker combined with behaviour change resources on inactive adolescents' physical activity. No significant intervention effects were found for accelerometer-assessed daily MVPA immediately postintervention (12-weeks). At 6-months post-intervention, adolescents in the intervention group engaged in significantly less MVPA than those in the wait-list control group. No significant intervention effects were found for self-reported physical activity immediately post-intervention or at 6 months post-intervention.

Little research has examined the effects of wearable activity trackers on youth physical activity, either alone or in combination with other strategies. Despite multicomponent strategies showing promise for increasing physical activity in different populations [18], no intervention effects were found immediately postintervention in this study. This is largely consistent with previous research in children and adolescents that has used wearable activity trackers either alone or in combination with different strategies (e.g. social media, faceto-face education sessions) in clinical and non-clinical populations [22, 24, 29, 30, 49]. It should be noted though that only one study included adolescents living in socioeconomically disadvantaged areas [24]. Moreover, the majority typically examined the feasibility, acceptability and preliminary efficacy of different wearable activity tracker interventions in children and adolescents, which may not have been sufficiently powered to detect changes in daily MVPA $[11,18]$.

In contrast to a number of previous studies $[23,24,49$, 50], RAW-PA was designed to be delivered online, and adolescents could access the behaviour change resources in their own time in a flexible, interactive way [31]. The behaviour change resources and materials were codesigned with the target population (adolescents), lowcost strategies were incorporated into the intervention to facilitate implementation, and the online delivery was utilised given its reach, accessibility, and the potential for wider scale up [31, 43]. However, the lack of significant findings immediately post-intervention suggests that the behaviour change resources and strategies provided online may not have been sufficient for increasing adolescents' activity levels. Indeed, these results indicate that digitally delivered interventions may need to be supplemented with more intensive or face-to-face support to increase activity levels, particularly as engagement with the Facebook group and the weekly challenges/missions were low during the intervention [43]. Such strategies may include the provision of tailored physical activity advice (e.g. how to be active), the development of support structures, or for content to be delivered in partnership with teachers or parents $[18,24,50,51]$. Studies that have only provided wearable activity trackers found that such minimalist strategies may initially increase awareness of activity levels but may not be 


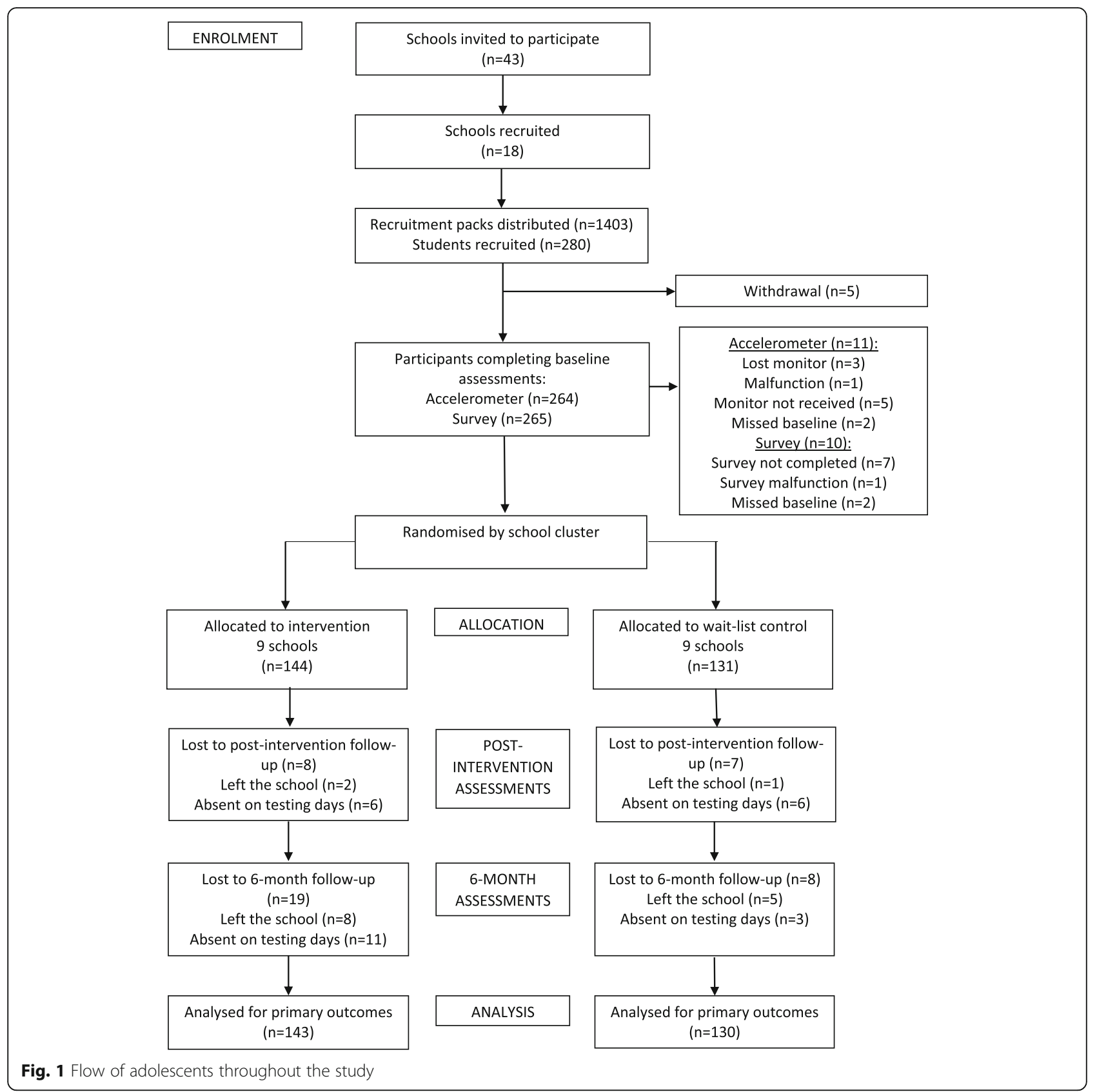

Table 1 Baseline characteristics of study sample (mean \pm SD; unless specified)

\begin{tabular}{llll}
\hline & Intervention & Wait-list Control & Whole sample \\
\hline Age (years) & $13.8(0.4)$ & $13.7(0.4)$ & $13.7(0.4)$ \\
Female students (\%) & 48.6 & 56.4 & 52.3 \\
Moderate- to vigorous-intensity physical activity (min/d) & $36.6(19.3)$ & $39.1(18.4)$ & $37.8(18.9)$ \\
Self-reported physical activity (days) & $2.8(1.8)$ & $2.8(1.7)$ & $2.8(1.8)$ \\
\hline
\end{tabular}


Table 2 Intervention effects on physical activity outcomes by intervention group immediately post-intervention and 6-month postintervention

\begin{tabular}{|c|c|c|c|c|c|c|}
\hline & \multicolumn{3}{|c|}{ Partially-adjusted model $^{\mathbf{b}}$} & \multicolumn{3}{|c|}{ Fully-adjusted model ${ }^{c}$} \\
\hline & $\bar{\beta}$ & $95 \% \mathrm{Cl}$ & $\overline{p \text {-value }}$ & $\bar{\beta}$ & $95 \% \mathrm{Cl}$ & $p$-value \\
\hline \multicolumn{7}{|l|}{ Accelerometry } \\
\hline \multicolumn{7}{|c|}{ Immediately post-intervention MVPA (min/d) } \\
\hline Whole sample & 0.7 & -3.47 to 4.89 & 0.76 & 0.5 & -3.54 to 4.50 & 0.81 \\
\hline Males & -0.9 & -7.14 to 5.37 & 0.78 & -0.1 & -6.45 to 6.16 & 0.96 \\
\hline Females & -0.02 & -5.16 to 5.11 & 0.99 & 0.4 & -4.66 to 5.56 & 0.86 \\
\hline \multicolumn{7}{|c|}{ 6-month post-intervention MVPA $(\mathrm{min} / \mathrm{d})^{a}$} \\
\hline Whole sample & -4.4 & -8.60 to -0.24 & 0.04 & -5.0 & -9.07 to -0.96 & 0.02 \\
\hline Males & -10.9 & -17.46 to -4.38 & 0.001 & -11.0 & -17.57 to -4.48 & 0.001 \\
\hline Females & -0.3 & -5.38 to 4.78 & 0.91 & -0.03 & -5.06 to 5.01 & 0.99 \\
\hline \multicolumn{7}{|l|}{ Self-report } \\
\hline \multicolumn{7}{|c|}{ Immediately post-intervention PA (days) ${ }^{a}$} \\
\hline Whole sample & 0.2 & -0.17 to 0.62 & 0.26 & 0.2 & -0.17 to 0.62 & 0.27 \\
\hline Males & 0.1 & -0.54 to 0.71 & 0.79 & 0.09 & -0.54 to 0.71 & 0.79 \\
\hline Females & 0.3 & -0.16 to 0.82 & 0.19 & 0.4 & -0.12 to 0.85 & 0.14 \\
\hline \multicolumn{7}{|c|}{ 6-month post-intervention PA (days) ${ }^{a}$} \\
\hline Whole sample & 0.2 & -0.25 to 0.55 & 0.46 & 0.1 & -0.26 to 0.54 & 0.49 \\
\hline Males & 0.02 & -0.61 to 0.65 & 0.95 & 0.02 & -0.61 to 0.66 & 0.95 \\
\hline Females & 0.2 & -0.26 to 0.73 & 0.35 & 0.3 & -0.21 to 0.77 & 0.27 \\
\hline
\end{tabular}

${ }^{\mathrm{a}}$ Difference between intervention and control group; significant differences are bolded

Cl Confidence interval, MVPA Moderate- to vigorous-intensity physical activity, PA Physical activity

bPartially adjusted model: adjusted for baseline outcome values and accelerometer wear time (for MVPA outcome only)

'Fully-adjusted model: additionally adjusts for baseline age, sex, wave of data collection

sufficient for increasing activity levels [22, 52]. Moreover, it is possible that the wearable activity tracker itself may have contributed to the lack of intervention effects. Despite pilot testing the Fitbit Flex with adolescents and addressing potential barriers to use within the RAW-PA intervention [31, 36], the Fitbit Flex has a limited display and requires the use of the accompanying app to obtain information concerning activity levels. Previous research has shown that utilising mobile phone data to view such data in an app was a barrier to use, regardless of socioeconomic status $[36,53]$. Furthermore, the RAW-PA implementation evaluation found that while the Fitbit Flex was perceived as being easy to use [43], students considered it required effort to use it (e.g. charge and sync [54]). This may have resulted in a lack of engagement by the adolescents with the specific physical activity feedback provided by the Fitbit Flex as intended during the intervention, which in turn could explain the null effects observed for daily MVPA.

The lower MVPA engagement in the intervention group at 6-months post-intervention is attributable to the declines observed in males. This contrasts with findings of a previous study that showed significantly lower sedentary time at 8-months follow-up for males when a wearable activity tracker was combined with web-based tailored physical advice [30], though interestingly this change did not result in increased physical activity of any intensity. Notably, neither the current study or that of Slootmaker and colleagues [30] found any effects on females' activity levels 6- and 8-months postintervention, respectively, suggesting that wearable activity trackers may have limited effects on females' physical activity levels. To date, only one study has reported lower MVPA engagement after using wearable activity trackers, albeit over a shorter time period [55]. Kerner and colleagues found declines in MVPA of $9.5 \mathrm{~min}$ per day after adolescents were provided with a Fitbit Charge for 5 weeks, attributing this change to lowered autonomous motivation [55]. It is possible that wearable activity trackers may negatively impact motivation to be active, particularly if the wearer fails to achieve a set activity goal [56] and focuses on the physical activity outcome (e.g. total steps) rather than the process $[57,58]$. It is difficult to explain, however, whether this may have resulted in changes at 6-months post-intervention but not immediately post-intervention in the present study, particularly as the implementation evaluation found that few males reported wearing their Fitbit Flex in the last 
week of the intervention [43]. It may be that the use of the wearable activity tracker resulted in a loss of intrinsic motivation over time, and that the devices instead created a dependence on achieving outcomes and rewards [59], with these effects manifested at 6-months postintervention. There is a need for studies utilising wearable activity trackers to examine longer-term effects on physical activity levels after the conclusion of an intervention [60]. This would provide important insights into whether use of this technology may have unintended negative effects on adolescents' physical activity over time, and what factors may explain any observed changes.

No effects were observed for self-reported physical activity either immediately or at 6-month postintervention. This is consistent with the findings of Bronikowski and colleagues [56] who examined whether specific or 'do your best' goals increased youth physical activity levels, assessed using the same self-report measure [44], albeit over an 8-week period. Previous research has demonstrated that inactive adolescents tend to overestimate their activity levels and intensity, and may be unware of how much daily activity that they need to engage in [61]. It has been suggested that the feedback provided by the Fitbit Flex may increase adolescents' awareness of their activity levels $[36,62]$, which may subsequently encourage them to reflect about the meaning of these data and whether there were any discrepancies between how active they thought they were and actually were [51]. This reflective process may have resulted in little change in self-reported physical activity levels postintervention. However, there are other potential explanations for the lack of significant findings. For example, while some studies in youth have shown that wearable activity trackers increase motivation to be active, at least in the short-term [63, 64], others have questioned whether increased awareness results in changes in activity levels [52, 62, 65]. Moreover, despite the behaviour change resources and delivery strategy being developed using participatory approaches [31], the implementation evaluation suggested that the delivered intervention may not have met the needs or expectations of the adolescents as engagement with the Facebook group and materials declined over time [43]. This is consistent with a recent study that showed no effects on adolescents' physical activity despite considerable input from the target group [66]. There is a need for further research to establish the impact of wearable activity trackers, either alone or in combination with additional strategies, on adolescents' physical activity levels, and examine what factors may be critical for changing behaviour.
This was one of the first studies to examine the effect of combining wearable activity trackers and behaviour change resources on inactive adolescents living in areas of socio-economic disadvantage. Strengths of the study include the cluster-randomised controlled trial design, the grounding of the intervention in theory, the inclusion of both device-based and subjective assessments of physical activity, and delivering the intervention in an ecologically valid setting [67]. However, several limitations should be acknowledged. Firstly, the Fitbit Flex provided limited feedback to participants, which meant that they needed to engage with the app or website to view their activity data in detail [54]. This may have impacted on their ability to self-monitor activity levels in real-time and ascertain progress against set-goals. Second, while the retention rate was relatively high in this study, compliance with the accelerometer measure was low. Complete valid data were provided by approximately half of the sample, though this is similar to previous trials [66]. Third, recruitment into the study was based on self-reporting against inclusion criteria. It is not known how many adolescents were eligible to participate in the study, and those who agreed to participate may not necessarily represent the wider population.

\section{Conclusion}

Combining a wearable activity tracker with online digital behaviour change resources was not effective in increasing the physical activity of adolescents attending schools in socio-economically disadvantaged areas immediately postintervention or at 6-month post-intervention compared to wait-list control participants. Lower engagement in MVPA 6-months post-intervention was observed for males but not for females, though it is unclear why this finding was observed. Future research is needed to better understand whether wearable activity trackers combined with appropriately engaging digital resources can effectively promote physical activity for adolescents, particularly for males.

\section{Supplementary Information}

The online version contains supplementary material available at https://doi. org/10.1186/s12966-021-01110-1.

Additional file 1. RAW-PA consort statement.

Additional file 2. The TIDieR (Template for Intervention Description and Replication) Checklist for RAW-PA.

Additional file 3: Table S1. Completer's analysis of intervention effects on physical activity outcomes by intervention group post-intervention and 6-month follow-up.

\section{Acknowledgements}

The authors thank the schools and students for participating in this study. The authors also gratefully acknowledge the contribution of all project staff, especially Kate Dullaghan, Dr. Felicity J. Pendergast, Stephanie Renehan, Dr Stephanie Chappel, Sophie Aarts, Kara Richards, Tom Steele, Sarah Tighe and Holly Beswick. 


\section{Authors' contributions}

NDR designed and led the study, developed the analysis plan, undertook statistical analyses, interpreted the results, and drafted the manuscript. AT, JS, $\mathrm{KB}, \mathrm{SM}, \mathrm{HB}$, and $\mathrm{SKL}$ contributed to the study design and interpretation of results. SKL collected data and assisted with data processing. All authors were significantly involved in critically revising the manuscript for intellectual content and have read and approved the final manuscript.

\section{Funding}

This study was supported by a VicHealth Innovation Research Grant. NDR is supported by a National Heart Foundation of Australia (NHFA) Future Leader Fellowship [Award ID 101895]. AT was supported by a NHFA Future Leader Fellowship [Award ID 100046] at the time of the study. KB was supported by a National Health and Medical Research Council (NHMRC) Principal Research Fellowship [APP1042442] at the time of the study. JS is supported by a NHMRC Leadership Level 2 Investigator Grant [APP1176885]. The content of this manuscript is the responsibility of the authors and does not necessarily reflect the views of the funding bodies.

\section{Availability of data and materials}

The datasets generated and/or analysed during the current study are not publically available due to ethics board requirements but are available from the corresponding author on reasonable request and pending approval from the relevant ethics committees.

\section{Declarations}

\section{Ethics approval and consent to participate}

Students provided written informed parental consent and student assent to participate in the study. Ethics approval for this study was received from the Deakin University Human Research Ethics Committee (2016-179) and the Victorian Department of Education and Training.

\section{Consent for publication}

Not applicable.

\section{Competing interests}

NDR and JS declare involvement in a start-up technological company. The remaining authors declare that they have no competing interests.

\section{Author details}

'Institute for Physical Activity and Nutrition (IPAN), School of Exercise and Nutrition Sciences, Deakin University, Geelong, Australia. ${ }^{2}$ Learning Futures, Deakin University, Burwood, Victoria, Australia.

\section{Received: 18 August 2020 Accepted: 11 March 2021}

Published online: 12 April 2021

\section{References}

1. Janssen I, LeBlanc A. Systematic review of the health benefits of physica activity and fitness in school-aged children and youth. Int J Behav Nutr Phys Act. 2010;7(1):40. https://doi.org/10.1186/1479-5868-7-40.

2. Poitras VJ, Gray CE, Borghese MM, Carson V, Chaput J-P, Janssen I, Katzmarzyk PT, Pate RR, Connor Gorber S, Kho ME, Sampson M, Tremblay MS. Systematic review of the relationships between objectively measured physical activity and health indicators in school-aged children and youth. Appl Physiol Nutr Metab. 2016;41(6 (Suppl. 3)):S197-239. https://doi.org/1 0.1139/apnm-2015-0663.

3. Hallal PC, Andersen LB, Bull FC, Guthold R, Haskel LW, Ekelund U, et al. Global physical activity levels: surveillance progress, pitfalls, and prospects. Lancet. 2012;380(9838):247-57. https://doi.org/10.1016/S01406736(12)60646-1.

4. Dumith SC, Gigante DP, Domingues MR, Kohl HW. Physical activity change during adolescence: a systematic review and pooled analysis. Int $J$ Epidemiol. 2011;40(3):685-98. https://doi.org/10.1093/ije/dyq272

5. Drummond MJN, Drummond CE, Dollman J, Abery L. Physical activity from early childhood to adolescence: a literature review of issues and interventions in disadvantaged populations. J Stud Wellbeing. 2010;4(2): 17-31.

6. Ball K. Traversing myths and mountains: addressing socioeconomic inequities in the promotion of nutrition and physical activity behaviours. Int J Behav Nutr Phys Act. 2015;12(1):142. https://doi.org/1 0.1186/s12966-015-0303-4.

7. Thompson WR. Worldwide survey of fitness trends for 2020. ACSMs Health Fit J. 2019;23(6):10-8. https://doi.org/10.1249/FIT.0000000000000526.

8. Statistica. Wearable technology - Statistics \& Facts. 2017. https://www.sta tista.com/topics/1556/wearable-technology/. Accessed 8 Feb 2018.

9. McCallum C, Rooksby J, Gray CM. Evaluating the impact of physical activity apps and wearables: interdisciplinary review. JMIR mHealth uHealth. 2018; 6(3):e58. https://doi.org/10.2196/mhealth.9054.

10. Lupton D. Health promotion in the digital era: a critical commentary. Health Promot Int. 2015;30(1):174-83. https://doi.org/10.1093/heapro/dau091.

11. Ridgers ND, McNarry MA, Mackintosh KA. Feasibility and effectiveness of using wearable activity trackers in youth: a systematic review. JMIR mHealth uHealth. 2016;4(4):e129. https://doi.org/10.2196/mhealth.6540.

12. Maher C, Ryan J, Ambrosi C, Edney S. Users' experiences of wearable activity trackers: a cross-sectional study. BMC Public Health. 2017;17(1):880. https:// doi.org/10.1186/s12889-017-4888-1.

13. Michie S, Richardson M, Johnston M, Abraham C, Francis J, Hardeman W, Eccles MP, Cane J, Wood CE. The behavior change technique taxonomy ( $\mathrm{V} 1)$ of 93 hierarchically clustered techniques: building an international consensus for the reporting of behavior change interventions. Ann Behav Med. 2013;46(1):81-95. https://doi.org/10.1007/ s12160-013-9486-6.

14. Lyons EJ, Lewis ZH, Mayrsohn BG, Rowland JL. Behavior change techniques implemented in electronic lifestyle activity monitors: a systematic content analysis. J Med Internet Res. 2014;16(8):192.

15. Duncan M, Murawski B, Short CE, Rebar AL, Schoeppe S, Alley S, Vandelanotte C, Kirwan M. Activity trackers implement different behavior change techniques for activity, sleep, and sedentary behaviors. Interact J Med Res. 2017;6(2):e13. https://doi.org/10.2196/ijmr.6685.

16. Evenson KR, Goto MM, Furberg RD. Systematic review of the validity and reliability of consumer-wearable activity trackers. Int J Behav Nutr Phys Act. 2015;12(1):159. https://doi.org/10.1186/s12966-015-0314-1.

17. Lewis ZH, Lyons EJ, Jarvis JM, Baillargeon J. Using an electronic activity monitor system as an intervention modality: a systematic review. BMC Public Health. 2015;15(1):585. https://doi.org/10.1186/s12889-015-1947-3.

18. Cajita MI, Kline CE, Burke LE, Bigini EG, Imes CC. Feasible but not yet efficacious: a scoping review of wearable activity monitors in interventions targeting physical activity, sedentary behavior, and sleep. Current Epidemiol Rep. 2020;7(1):25-38. https://doi.org/10.1007/s40471-020-00229-2.

19. Cadmus-Bertram LA, Marcus BH, Patterson RE, Parker BA, Morey BL. Randomized trial of a Fitbit-based physical activity intervention for women. Am J Prev Med. 2015;49(3):414-8. https://doi.org/10.1016/j.a mepre.2015.01.020.

20. Finkelstein EA, Haaland BA, Bilger M, Sahasranaman A, Sloan RA, Nang EE, et al. Effectiveness of activity trackers with and without incentives to increase physical activity (TRIPPA): a randomised controlled trial. Lancet Diabetes Endocrinol. 2016;4(12):983-95. https://doi.org/10.1016/S22138587(16)30284-4.

21. Wang JB, Cadmus-Bertram LA, Natarajan L, White MM, Madanat $H$, Nichols JF, Ayala GX, Pierce JP. Wearable sensor/device (Fitbit one) and SMS textmessaging prompts to increase physical activity in overweight and obese adults: a randomized controlled trial. Telemed J E Health. 2015;21(10):78292. https://doi.org/10.1089/tmj.2014.0176.

22. Gaudet J, Gallant F, Belanger M. A bit of fit: minimalist intervention in adolescents based on a physical activity tracker. JMIR mHealth uHealth. 2017:5(7):e92. https://doi.org/10.2196/mhealth.7647.

23. Hooke MC, Gilchrist L, Tanner L, Hart N, Withycombe JS. Use of a fitness tracker to promote physical activity in children with acute lymphoblastic leukemia. Pediatr Blood Cancer. 2016;63(4):684-9. https://doi.org/10.1002/ pbc.25860.

24. Evans EW, Abrantes AM, Chen E, Jelaian E. Using novel technology within a school-based setting to increase physical activity: a pilot study in school-age children from a low-income, urban community. Biomed Res Int. 2017; 4271483:1.

25. Chen J-L, Guedes CM, Cooper BA, Lung AE. Short-term efficacy of an innovative mobile phone technology-based intervention for weight management for overweight and obese adolescents: pilot study. Interact J Med Res. 2017;6(2):e12. https://doi.org/10.2196/ijmr.7860.

26. Lau PWC, Lau EY, Wong DP, Ransdell L. A systematic review of information and communication technology-based interventions for promoting 
physical activity behavior change in children and adolescents. J Med Internet Res. 2011;13(3):e48. https://doi.org/10.2196/jmir.1533.

27. Schoenfelder E, Moreno M, Wilner M, Whitlock KB, Mendoza JA. Piloting a mobile health intervention to increase physical activity for adolescents with ADHD. Prev Med Rep. 2017;6:210-3. https://doi.org/1 0.1016/j.pmedr.2017.03.003.

28. Australian Bureau of Statistics. Household Use of Information Technology, Australia, 2012-13. Canberra: Australian Bureau of Statistics; 2013. Report No.: 8146.0

29. Mendoza JA, Baker KS, Moreno MA, Whitlock K, Abbey-Lambertz M, Waite A, Colburn T, Chow EJ. A Fitbit and Facebook mHealth intervention for promoting physical activity among adolescent and young adult childhood cancer survivors: a pilot study. Pediatr Blood Cancer. 2017;64(12):e26660. https://doi.org/10.1002/pbc.26660.

30. Slootmaker SM, Chinapaw MJM, Seidell JC, van Mechelen W, Schuit AJ. Accelerometers and internet for physical activity promotion in youth? Feasibility and effectiveness of a minimal intervention [ISRCTN93896459]. Prev Med. 2010;51(1):31-6. https://doi.org/10.1016/j.ypmed.2010.03.015

31. Ridgers ND, Timperio A, Brown H, Ball K, Macfarlane S, Lai SK, Richards K Ngan W, Salmon J. A cluster-randomised controlled trial to promote physical activity in adolescents: the raising awareness of physical activity (RAW-PA) study. BMC Public Health. 2017;17(1):6. https://doi.org/10.1186/s12 889-016-3945-5

32. Campbell MK, Piaggio G, Elbourne DR, Altman DG. Consort 2010 statement: extension to cluster randomised trials. Br Med J. 2012;345(sep04 1):e5661. https://doi.org/10.1136/bmj.e5661.

33. Hoffman TC, Glasziou PP, Boutron I, Milne R, Perera R, Moher D, et al. Better reporting of interventions: template for intervention description and replication (TIDieR) checklist and guide. Br Med J. 2014;348(mar07 3):g1687. https://doi.org/10.1136/bmj.g1687.

34. Australian Bureau of Statistics. Census of Population and Housing: SocioEconomic Indexes for Areas (SEIFA), Australia, 2011. http://www.abs.gov.au/a usstats/abs@.nsf/mf/2033.0.55.001. Accessed 20 Aug 2016.

35. Ekelund U, Luan J, Sherar LB, Esliger DW, Griew P, Cooper A, et al. Moderate to vigorous physical activity and aedentary time and cardiometabolic risk factors in children and adolescents. JAMA. 2012;307(7):704-12. https://doi. org/10.1001/jama.2012.156.

36. Ridgers ND, Timperio A, Brown H, Ball K, Macfarlane S, Lai SK, Richards K, Mackintosh KA, McNarry MA, Foster M, Salmon J. Wearable activity tracker use among Australian adolescents: usability and acceptability study. JMIR mHealth uHealth. 2018;6(4):e86. https://doi.org/10.2196/mhealth.9199.

37. Epstein LH. Integrating theoretical approaches to promote physical activity. Am J Prev Med. 1998;15(4):257-65. https://doi.org/10.1016/S0749-3 797(98)00083-X.

38. Bandura A. Social foundations of thought and action: a social cognitive theory. Englewood Cliffs: Prentice Hall; 1986

39. Trost SG, Ward DS, Moorhead SM, Watson PD, Riner W, Burke JR. Validity of the computer science and applications (CSA) activity monitor in children. Med Sci Sports Exerc. 1998;30(4):629-33. https://doi.org/10.1097/00005768-1 99804000-00023.

40. Freedson P, Pober D, Janz KF. Calibration of accelerometer output for children. Med Sci Sports Exerc. 2005;11(Suppl):S523-S30.

41. Cain KL, Sallis JF, Conway TL, Van Dyck D, Calhoon L. Using accelerometers in youth physical activity studies: a review of methods. J Phys Act Health. 2013;10(3):437-50. https://doi.org/10.1123/jpah.10.3.437.

42. Smith M, Taylor S, Iusitini L, Stewart T, Savila F, Tautolo E-L, et al. Accelerometer data treatment for adolescents: fitting a piece of the puzzle. Prev Med Rep. 2017;5:228-31. https://doi.org/10.1016/j.pmedr.201 6.12.010.

43. Koorts H, Salmon J, Timperio A, Ball K, Macfarlane S, Lai SK, Brown H, Chappel SE, Lewis M, Ridgers ND. Implementation evaluation of a wearable technology intervention to increase adolescent physical activity: translatability into practice. J Med Internet Res. 2020;22(8):e13573. https:// doi.org/10.2196/13573

44. Prochaska JJ, Sallis JF, Long B. A physical activity screening measure for use with adolescents in primary care. Arch Pediatr Adolesc Med. 2001;155(5): 554-9. https://doi.org/10.1001/archpedi.155.5.554.

45. Ridgers ND, Timperio A, Crawford D, Salmon J. Validity of a brief self-report instrument for assessing compliance with physical activity guidelines amongst adolescents. J Sci Med Sport. 2012 Mar;15(2):136-41. https://doi. org/10.1016/j.jsams.2011.09.003.
46. White IR, Carpenter J, Horton NJ. Including all individuals is not enough : lessons for intention-to-treat analysis. Clin Trials. 2012;9(4):396-407. https:// doi.org/10.1177/1740774512450098.

47. Twisk JWR. Applied multilevel analysis. Cambridge: Cambridge University Press; 2006. https://doi.org/10.1017/CBO9780511610806.

48. Sterne JAC, White IR, Carlin JB, Spratt M, Royston P, Kenward MG, Wood AM Carpenter JR. Multiple imputation for missing data in epidemiological and clinical research: potential and pitfalls. Br Med J. 2009;338(29):b2393. https:// doi.org/10.1136/bmj.b2393.

49. Heale LD, Dover S, Goh YI, Maksymiuk VA, G. D W, et al. A wearable activity tracker intervention for promoting physical activity in adolescents with juvenile idiopathic arthritis: A pilot study. Pediatr Rheumatol Online J. 2018;16:66

50. Remmert JE, Woodworth A, Chau L, Schumacher LM, Butryn ML, Schneider M. Pilot trial of an acceptance-based behavioral intervention to promote physical activity among adolescents. J Sch Nurs. 2019;35(6):449-61. https:// doi.org/10.1177/1059840518786782.

51. Saksono H, Castaneda-Sceppa C, Hoffman J, El-Nasr MS, Morris V, Parker AG. Social reflections on fitness tracking data: A study with families in low-SES neighbourhoods. In: CHI Conference on Human Factors in Computing Systems Proceedings; May 4-9 2019. Glasgow, New York: ACM; 2019.

52. Schaefer SE, Ching CC, Breen H, German BJ. Wearing, thinking, and moving: testing the feasibility of fitness tracking with urban youth. Am J Health Educ. 2016;47(1):8-16. https://doi.org/10.1080/19325037.2015.1111174.

53. Smith JJ, Morgan PJ, Plotnikoff RC, Dally KA, Salmon J, Okely AD, Finn TL, Lubans DR. Smart-phone obesity prevention trial for adolescent boys in low-income communities: the ATLAS RCT. Pediatrics. 2014;134(3):e723-e31. https://doi.org/10.1542/peds.2014-1012.

54. Drehlich M, Naraine M, Rowe K, Lai SK, Salmon J, Brown H, Koorts H, Macfarlane S, Ridgers ND. Using the technology acceptance model to explore adolescents' perspectives on combining technologies for physical activity promotion within an intervention: usability study. J Med Internet Res. 2020;22(3):e15552. https://doi.org/10.2196/15552.

55. Kerner C, Burrows A, McGrane B. Health wearables in adolescents: implications for body satisfaction, motivation and physical activity. Int J Health Promot Educ. 2019:57(4):191-202. https://doi.org/10.1080/14635240.2 019.1581641.

56. Bronikowski M, Bronikowska M, Glapa A. Do they need goals or support? A report from a goal-setting intevention using physical activity monitors in youth. Int J Environ Res Public Health. 2016;13:914.

57. Kerner C, Goodyear VA. The motivational impact of wearable healthy lifestyle technologies: a self-determination perspective on Fitbits with adolescents. Am J Health Educ. 2017;48(5):287-97. https://doi.org/10.1080/1 9325037.2017.1343161.

58. Kosma M, Buchanan DR. "Connect," Log It, Track It, Go! Techne - not technology - and embodiment to achieve phronesis in exercise promotion. Quest. 2018;70(1):100-13. https://doi.org/10.1080/00336297.2017.1355818.

59. Ryan RM, Deci EL. Chapter 2 - When rewards compete with nature: The undermining of intrinsic motivation and Self-Regulation. In: Sansone C, Harackiewicz JM, editors. Intrinsic and extrinsic motivation: The search for optimal motivation and performance: Academic Press; 2000. p. 13-54. https://doi.org/10.1016/B978-012619070-0/50024-6.

60. Böhm B, Karwiese SD, Böhm H, Oberhoffer R. Effects of mobile health including wearable activity trackers to increase physical activity outcomes among healthy children and adolescents: systematic review. JMIR mHealth uHealth. 2019;7(4):e8298. https://doi.org/10.2196/mhealth.8298.

61. Corder K, van Sluijs EMF, Goodyer I, Ridgway CL, Steele RM, Bamber D, Dunn V, Griffin SJ, Ekelund U. Physical activity awareness of British adolescents. Arch Pediatr Adolesc Med. 2011;165(7):603-9. https://doi.org/1 0.1001/archpediatrics.2011.94

62. Shin G, Jarrahi MH, Fei Y, Karami A, Gafinowitz N, Byun A, Lu X. Wearable activity trackers, accuracy, adoption, acceptance and health impact: a systematic literature review. J Biomed Inform. 2019;93:103153. https://doi. org/10.1016/j.jbi.2019.103153.

63. Metos J, Gren L, Brusseau T, Moric E, O'Toole K, Mokhtari T, et al. Adolescent girls' reactions to nutrition and physical activity assessment tools and insight into lifestyle habits. Health Educ J. 2018;77(1):85-95. https://doi.org/1 $0.1177 / 0017896917734575$.

64. Voskuil VR, Stroup S, Leyden M. Acceptability and usability of a wearable activity tracker and application among inactive adolescent girls. Phys Act Health. 2020;4(1):52-61. https://doi.org/10.5334/paah.51. 
65. Muller J, Hoch A-M, Zoller V, Oberhoffer R. Feasibility of physical activity assessment with wearable devices in children aged 4-10 years - a pilot study. Front Pediatr. 2018;6:5. https://doi.org/10.3389/fped.2018.00005.

66. Corder K, Werneck AO, Jong ST, Hoare E, Brown HE, Foubister C, Wilkinson PO, van Sluijs EMF. Pathways to increasing adolescent physical activity and wellbeing: a mediation analysis of intervention components designed using a participatory approach. Int J Environ Res Public Health. 2020;17(2):390. https://doi.org/10.3390/ijerph17020390.

67. Vandelanotte C, Duncan MJ, Kolt GS, Caperchione CM, Savage TN, Van Itallie A, et al. More real-world trials are needed to establish if web-based physical activity interventions are effective. Br J Sports Med. 2019;53(24):1553-4. https://doi.org/10.1136/bjsports-2018-099437.

\section{Publisher's Note}

Springer Nature remains neutral with regard to jurisdictional claims in published maps and institutional affiliations.

Ready to submit your research? Choose BMC and benefit from:

- fast, convenient online submission

- thorough peer review by experienced researchers in your field

- rapid publication on acceptance

- support for research data, including large and complex data types

- gold Open Access which fosters wider collaboration and increased citations

- maximum visibility for your research: over $100 \mathrm{M}$ website views per year

At BMC, research is always in progress.

Learn more biomedcentral.com/submissions 